\title{
Determination of Atmospheric Turbidity and its Correlation with Climatologically Parameters
}

\author{
U. Ali Rahoma and A.H. Hassan
}

Department of Solar Research, National Research Institute of Astronomy and Geophysics, Helwan, Egypt

Received 2012-07-15, Revised 2012-09-20; Accepted 2012-12-28

\begin{abstract}
Study of Atmospheric turbidity is important for purposes of meteorology, ecology, climatology and monitoring of atmospheric pollution. Linke Turbidity factor (LT) is commonly used to model the attenuation of solar radiation in the atmosphere. The probable dependence on the water vapor content of the relationship linking LT to Angstrom's turbidity coefficient B, is discussed. In this study, a procedure for calculation of Linke turbidity factor is adopted using pyrheliometric measurements by Egyptian Typical Meteorological Year (ETMY) at a Thirteen stations at Egypt, during (from 1969 to 2006). Monthly variations of the LT turbidity factor are found in the three studied months, with a maximum in August and a minimum in July. Detailed studies on the effect of urbanization and industrialization on global solar radiation and the percentage values of radiation loss in the atmosphere, at Egypt, have been performed. The high values of LT (5-6) and B (0.48-0.52) lies between Lat. $28^{\circ} \mathrm{N}-30^{\circ} \mathrm{N}$, low values of $\mathrm{LT}<3.5$ and $\mathrm{B}<0.3$ below of Lat. $26^{\circ} \mathrm{N}$. 8 cities of the thirteen city used in the study are located in the maximum values of this period is the most civilized cities and concentrated a large part of the population which constitutes a danger to the health of the population and the spread of diseases resulting from atmospheric turbidity.
\end{abstract}

Keywords: Direct Solar Radiation, Atmospheric Turbidity, Climatologically Parameter

\section{INTRODUCTION}

The Linke turbidity factor refers to the whole spectrum, that is, overall spectrally integrated attenuation, which includes presence of gaseous water vapor and aerosols. The increase of LT is an indication for increasing atmospheric turbidity level (pollution). The additional attenuation caused by these two processes is known to be due to the turbidity of the atmosphere (Linke, 1922; Adeyefa and Adedokun, 1991; Angstrom, 1929; 1961; Bird, 1984; Diouri et al., 2000; Gueymard, 1994; Rahoma and Hassan, 2010). Among several turbidity coefficients the most frequently used are the Linke turbidity factor, LT (Linke, 1922) and the Angstrom turbidity coefficient, B (Angstrom, 1961). Atmospheric turbidity indices have been estimated in many locations, either on the basis of spectral irradiance or on all wavelengths direct irradiance data (Katz et al., 1982; Shaw, 1921; Hgazy, 1976; Pemund et al., 2003; Robaa, 2009; Zakey et al., 2004). Also, the influence of some atmospheric parameters on the annual variation of atmospheric turbidity has been studied (El-Hussainy and Omran, 1998; Abdelrahman et al., 1988). Here, we estimate the atmospheric turbidity indices for different latitude of the thirteen stations at Egypt. Thus, with this selection it is possible to study the Monthly variation of atmospheric turbidity.

\subsection{Brief Description of the Apparatus}

Hourly direct solar radiation measurements were recorded at thirteen stations at Egypt by an Eppley

Corresponding Author: U. Ali Rahoma, Department of Solar Research, National Research Institute of Astronomy and Geophysics, Helwan, Egypt 
normal incidence Pyrheliometer that measures the nearly collimated (i.e., parallel rays) radiation from the $0.5^{\circ} \mathrm{C}$ diameter solar disk. The uncertainty in the direct beam component is $0.5 \%$, or about $5 \mathrm{~W} \mathrm{~m}^{-2}$ at $1000 \mathrm{~W} \mathrm{~m}^{-2}$ direct irradiance. Simultaneously with the solar radiation measurements, relative humidity, air temperature, mean total cloud cover, vapor pressure, rising sand, surface pressure, wind direction and wind speed were measured and recorded continuously on diurnal records. These atmospheric data characterize the types of air mass prevalent over the location of the radiation measurements. Table 1, shows the description of the Egypt stations under studied and locality properties from 1969 to 2006 by ETMY (Egyptian Typical Meteorological Year) Using Design Conditions from "ASHRAE (2009)". The design conditions are carefully generated, from a period of record (typically 30 years) to be representative of that location covered the almost region at Egypt.

\section{MATERIALS AND METHODS}

Egypt is located between 22 to $32^{\circ} \mathrm{C} \mathrm{N}$ and 24 to $37^{\circ} \mathrm{C} \mathrm{E}$. Air pollution is a serious problem in the major cities of Egypt, particularly Cairo. One of the major causes is the large concentration of polluting industries in and around the urban residential areas, especially at Helwan (30 Km south Cairo) particularly in the steel, cement fertilizer and chemicals sectors which contribute to high ambient dust levels and $\mathrm{SO}_{2}$ that may be between 2 and 10 times maximum safe levels. Vehicle exhaust gases also contribute.

Egypt has only two seasons: A mild winter from November to April and a hot summer from May to October. The only differences between the seasons are variations in daytime temperatures and changes in prevailing winds. The elections of the monitoring sites have been chosen to cover the coastal and interior regions of Egypt. The average annual temperature increases moving southward from the Delta to the Sudanese border, where temperatures are similar to those of the open deserts to the east and west.

The concentrations of total suspended particulates in the air in urban centers are generally much higher than the WHO Guideline value. Urban solid waste burning, industrial waste generation, industrial heavy fuel use and diesel fuel consumption in the transport sector are the major sources of particulate air pollution (Shaltout et al., 1998). Agricultural burning also contributes on a seasonal basis. In addition to its health effects, air pollution impacts the cultural heritage by causing damage to priceless monuments. Solid waste is a growing environmental problem in Egypt. Inefficient collection, storage and disposal of municipal and hazardous wastes results in the spread of disease and localized pollution. A major proportion of the solid wastes generated in the more affluent suburbs of Cairo (where waste contains relatively valuable components) is collected, manually sorted and efficiently recycled. In the poorer city areas systems for collection and disposal are poorly developed and often waste accumulates and is just burned on the streets. Solid waste is deposited in open dumpsites close to settlements in desert areas.

The increasing incorporation of hazardous wastes into the general bulk waste stream poses increasing health risks, particularly for waste collection workers and waste pickers. Recent initiatives to control industrial pollution through increased monitoring and enforcement of standards at industrial facilities have led to overall improvements in the quality of the River Nile (Hamdy, 2006). Table 2, shows, the parameters for various degrees of atmospheric cleanliness (Leckner, 1978).

\subsection{Mathematical Formulations}

Linke (1922) himself recognized the variation of LT with air mass, but had little success in introducing a new extinction. The direct normal Irradiance (I) integrated over all wavelengths received at the earth's surface under clear sky conditions can be expressed as (Hussain et al., 2000). Link's turbidity factor can be derived from pyrheliometric measurements of the direct normal irradiance at ground level.

Table 1. The description of the Egypt stations under studied

\begin{tabular}{lcll}
\hline Egypt stations & Elevation $(\mathrm{m})$ & Latitude $(\mathrm{N})$ & Longitude $(\mathrm{E})$ \\
\hline Cairo & 74 & 3007 & 3123 \\
Aswan & 200 & 2401 & 3250 \\
Helwan & 141 & 2952 & 3119 \\
Asyut & 70 & 2700 & 3100 \\
Alexandria & 7 & 3112 & 2957 \\
Hurghada & 14 & 2709 & 3343 \\
Ismailia & 13 & 3036 & 3215 \\
Kharga & 73 & 2527 & 3032 \\
Luxor & 88 & 2540 & 3242 \\
Al-minya & 40 & 2804 & 3043 \\
Al-Arish & 32 & 3104 & 3349 \\
Rafah & 73 & 3122 & 3422 \\
Bahtim & 17 & 3015 & 3125 \\
\hline
\end{tabular}

Table 2. Parameters for various degrees of atmospheric cleanliness (Leckner, 1978)

\begin{tabular}{llll}
\hline Atmosphere & LT & B & Visibility $(\mathrm{km})$ \\
\hline Pure Rayleigh atmosphere & 1 & 0.00 & 340 \\
Clear, warm air & 2 & 0.10 & 28 \\
Turbid, Moist, warm air & 3 & 0.20 & 11 \\
Polluted atmosphere & $4-8$ & 0.40 & $<5$ \\
\hline
\end{tabular}


Angstrom turbidity parameters and aerosol optical thickness: A study over 500 solar beam spectra. As a result, a new wavelength pair for filter measurements is proposed to calculate the Angstrom parameters with the Voltz technie, namely, the pair $(0.400-0.750 \mu \mathrm{m})$. For the considered atmospheric conditions (continental urban aerosols), the mean value of the Angstrom parameter $\alpha$ is found to be $1.0 \pm 0.3$, which is relatively close to the conventional $\alpha=1.3$ if taking into account the variance. Ångstrom's turbidity coefficient (B) is an indication only of the amount of aerosols in the atmosphere (Angstrom, 1961). The experimental determination of $B$ and wavelength exponent $(\alpha)$ is accomplished by observing the attenuation of the direct solar irradiance at two particular wavelengths, where the absorption/scattering of the solar radiation are due to aerosol.

The wavelengths $\lambda=0.38 \mu \mathrm{m}$ and $\lambda=0.5 \mu \mathrm{m}$ are generally used to get the optimum optical thickness of the aerosol. For cloudless skies, the transmittance of aerosols can be expressed in terms of the individual transmittance of the different atmospheric parameters, According to the method derived by Louche et al. (1987).

It is also common to determine B from broadband pyrheliometer measurements when $\alpha$ is fixed at an arbitrary value. Large values of $\alpha$ indicate a relatively high ratio of small particles to large particles. The Angstrom coefficient is calculated from the following relation:

$$
\mathrm{B}=-\lambda^{\alpha}\left(\frac{1}{\mathrm{~m}} \operatorname{In} \frac{\mathrm{I}_{\lambda}}{\mathrm{I}_{\mathrm{o} \lambda}}+0.00897 \lambda^{-4.09}\right)
$$

where, $I_{0}$ is the extraterrestrial solar irradiance at normal incidence $\left(=1367 \mathrm{Wm}^{-2}\right)$. By definition, the Linke turbidity factor is estimated from the expression (Abdelrahman et al., 1988):

$$
\mathrm{LT}=-\left[\left(1 / \mathrm{m}\left(0.00897 \lambda^{-4.09}\right)\right)\left(\operatorname{In} \frac{\mathrm{I}_{\lambda} \mathrm{S}}{\mathrm{I}_{\mathrm{o} \lambda}}\right)\right]
$$

where, $\mathrm{S}$ is a factor that accounts for the Sun-Earth distance variation in Astronomical Unit (A.U), $m$ depends on the solar zenith angle $(\theta)$ is air mass the intercept and $\alpha$, is given by:

$$
\alpha=-\left[0.00897 \lambda^{\alpha-4.09}+\frac{\operatorname{InS}}{\mathrm{m}} \lambda^{\alpha}\right]
$$

\section{RESULTS}

Egypt's climate is semi-desert, characterized by hot dry summers, moderate winters and very little rainfall. Some cities have areas with strong wind, especially along the Red Sea and Mediterranean coasts. Sites with an annual average wind speed of $8.0-10.0 \mathrm{msec}^{-1}$ have been identified along the Red Sea coast and about 6.0$6.5 \mathrm{msec}^{-1}$ along the Mediterranean coast. The climate models all estimate a steady increase in air temperatures for Egypt, with little inter-model variance. Atmospheric turbidity depends on the local weather conditions and on the climate of the site. Generally, Generally, from Table 3 , it is clear that the monthly values of air temperature and vapor pressure both reached a maximum in July and lower values in January.

The average summer temperature is $26.2^{\circ} \mathrm{C}$, while that of winter is $12.8^{\circ} \mathrm{C}$, with an average difference between day and night of $10^{\circ} \mathrm{C}$. This great temperature difference promotes the formation of dew at dawn as the relative humidity of the air becomes generally high, especially during winter. Relative humidity fluctuates between $72 \%$ recorded in January and $57 \%$ recorded in May, with annual average wind velocity of $4 \mathrm{~m} \mathrm{~s}^{-1}$.

In general, late winter and spring tend to be winter, when the Khamasin winds blow over the Egyptian western desert. The use of the monthly mean might be crude because dust events are highly dependent on wind speed that is most variable on very short time scales. The fraction of time spent with the wind blowing in the various directions over the entire year.

Table 3. Monthly means variations of metrological parameters at Egypt of $T_{D}$, R.H, WS, WS, S.D, V.P and C.C

\begin{tabular}{lrrrrrrrrrrrr}
\hline & \multicolumn{1}{c}{ Jan. } & \multicolumn{1}{c}{ Feb. } & \multicolumn{1}{c}{ Mar. } & \multicolumn{1}{c}{ Apr. } & \multicolumn{1}{c}{ May } & \multicolumn{1}{c}{ Jun. } & \multicolumn{1}{l}{ Jul. } & \multicolumn{1}{c}{ Aug. } & \multicolumn{1}{c}{ Sep. } & Oct. & Nov. & Dec. \\
\hline TD & 19.400 & 21.20 & 24.7 & 28.8 & 31.4 & 34.40 & 35.00 & 35.10 & 33.10 & 30.00 & 23.9 & 21.20 \\
R.H & 59.500 & 54.10 & 49.3 & 44.1 & 41.9 & 44.50 & 46.40 & 47.90 & 50.50 & 53.60 & 58.00 & 59.50 \\
WS & 3.000 & 3.60 & 3.9 & 3.9 & 3.6 & 4.10 & 3.50 & 3.50 & 3.70 & 3.40 & 3.10 & 3.00 \\
WD & 207.000 & 206.00 & 171.0 & 178.0 & 132.0 & 179.00 & 175.00 & 192.00 & 112.00 & 144.00 & 131.00 & 175.00 \\
S.D & 7.000 & 7.90 & 8.4 & 9.4 & 10.5 & 11.80 & 11.40 & 11.10 & 10.10 & 9.40 & 8.01 & 7.04 \\
V.P & 9.000 & 9.00 & 9.8 & 10.9 & 12.8 & 16.40 & 21.40 & 20.50 & 19.40 & 16.50 & 12.90 & 10.30 \\
C.C & 2.580 & 2.33 & 2.3 & 1.9 & 0.8 & 0.49 & 0.56 & 0.87 & 0.93 & 0.91 & 1.80 & 1.75 \\
\hline
\end{tabular}

Where: TD: is the average day temperature $\left({ }^{\circ} \mathrm{C}\right)$; R.H: is the relative humidity (\%); WS: is the wind speed (m s-1); WD: is the wind direction (degree); S.D: is the bright sunshine duration (h); V.P: is the vapor pressure (hPa); C.C: is the total cloud cover. 


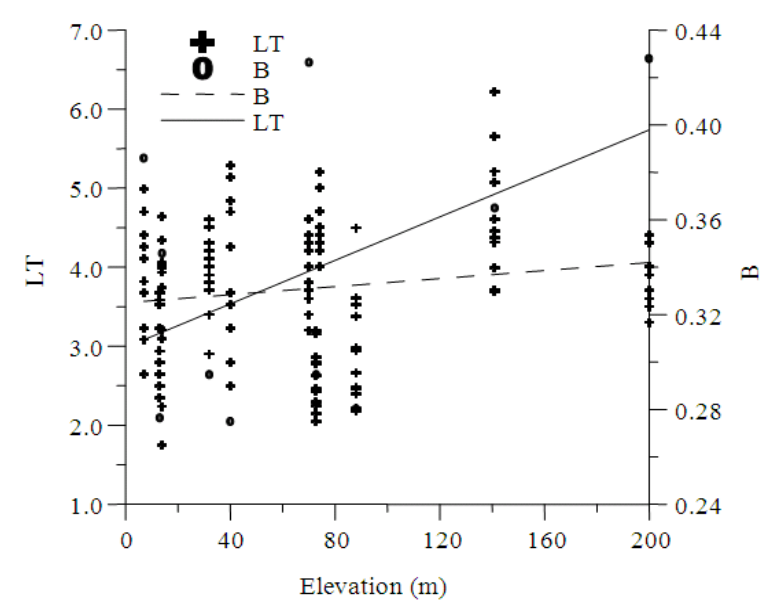

Fig. 1. Relationship between the LT, B and Elev

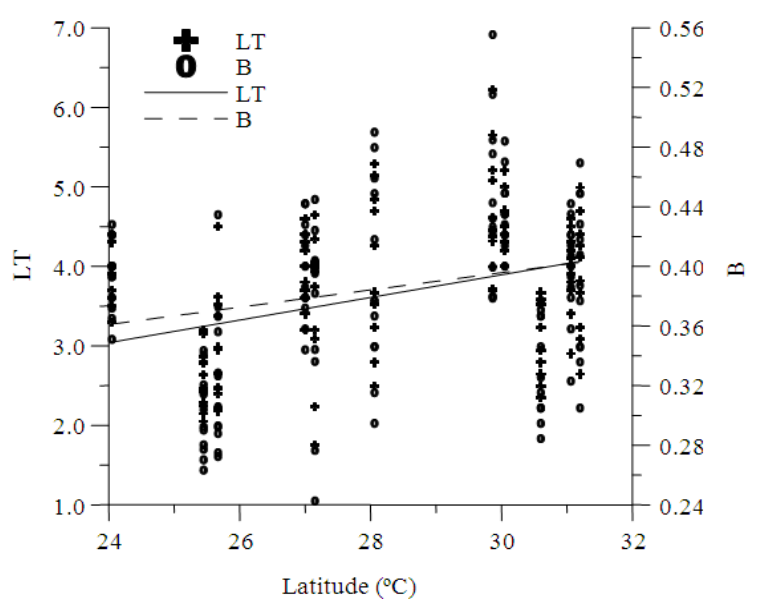

Fig. 2. Relationship between the LT, B and Lat

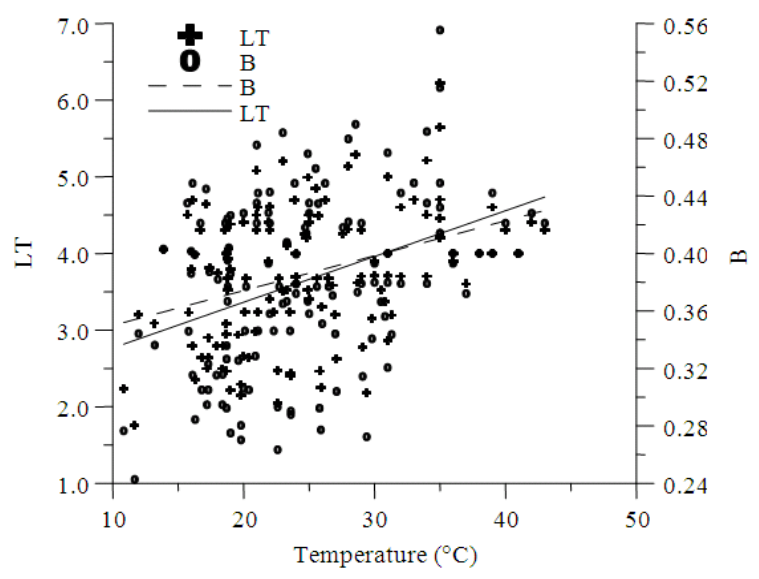

Fig. 3. Relationship between the LT, B and T

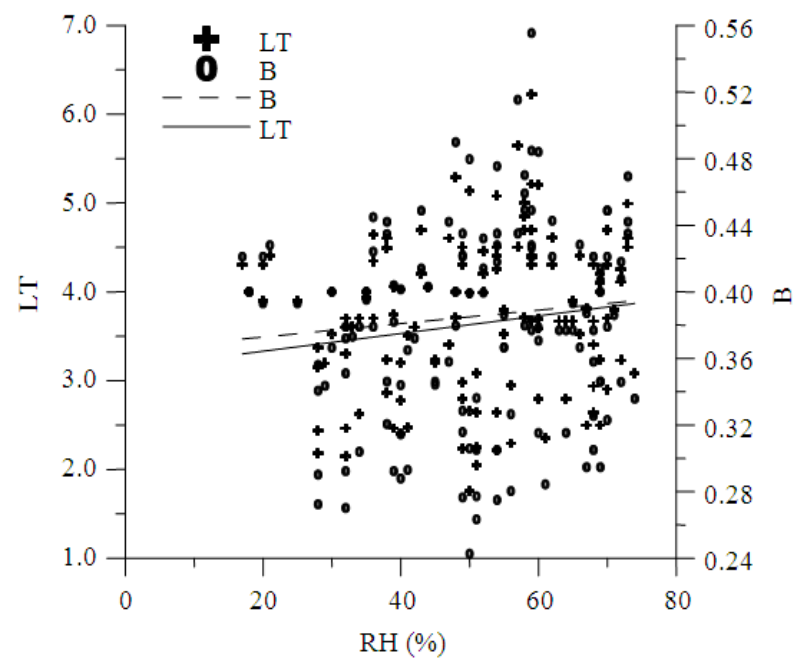

Fig. 4. Relationship between the LT, B and RH

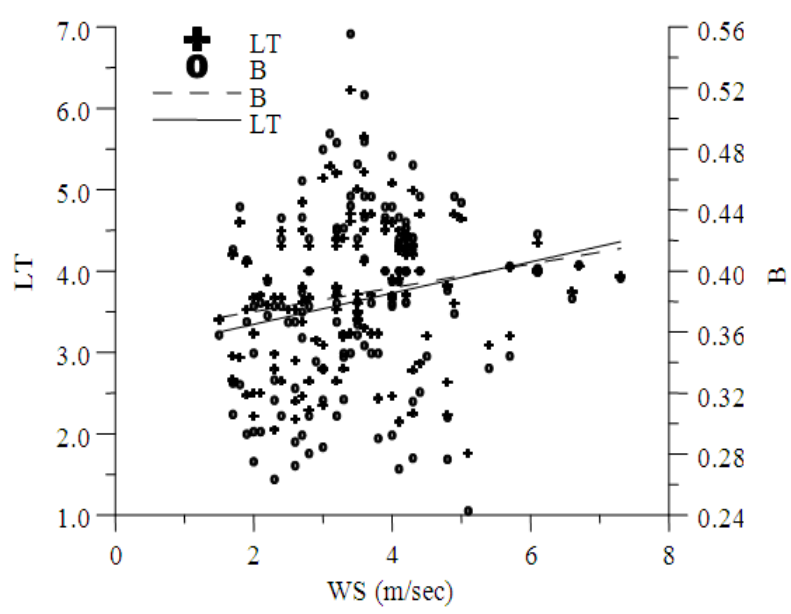

Fig. 5. Relationship between the LT, B and WS

Values do not sum to $100 \%$ because the wind direction is undefined when the wind speed is zero. The fraction of time spent with the wind blowing in the various directions on a daily basis. Figure 1-5 show the relationship between LT different parameters; Elevation, Latitude, air temperature, relative humidity and wind speed respectively. Figure 6-7 give use linear behavior as shown in Table 4. Figure 6-7 shows, the relation between the LT and Kt, Kd. Table 5 show, Univariate Statistics of different meteorological and LT, B variables. 
U. Ali Rahoma and A.H. Hassan / American Journal of Environmental Science 8 (6) (2012) 597-604

Table 4. Correlation of Linke turbidity with different parameter related to the equation $L T=a+b X$

\begin{tabular}{llr}
\hline X & $\mathrm{a}$ & $\mathrm{b}$ \\
\hline Elevation(Elev) & 3.73 & 0.0013 \\
Air temperature (T) & 2.60 & 0.0450 \\
Relative Humidity (RH) & 3.33 & 0.0070 \\
Wind Speed (WS) & 3.20 & 0.1400 \\
Latitude (Lat) & 0.11 & 0.1300 \\
Angstrom turbidity(B) & 1.71 & 14.2800 \\
\hline
\end{tabular}

Table 5. Univariate Statistics of different meteorological and LT, B variables

\begin{tabular}{|c|c|c|c|c|c|c|}
\hline Univariate Statistics & WS & $\mathrm{T}$ & RH & $\varphi$ & LT & B \\
\hline 50\%\%-tile: & 3.50 & 23.300 & 51.000 & 28.060 & 3.80 & 0.39 \\
\hline 99\%\%-tile: & 6.60 & 41.000 & 73.000 & 31.360 & 5.40 & 0.50 \\
\hline Minimum: & 1.50 & 10.840 & 17.000 & 24.080 & 1.75 & 0.24 \\
\hline Maximum: & 7.30 & 43.000 & 74.000 & 31.360 & 6.22 & 0.56 \\
\hline Mean: & 3.52 & 24.360 & 50.520 & 28.450 & 3.77 & 0.38 \\
\hline Median: & 3.50 & 23.430 & 51.000 & 28.960 & 3.81 & 0.39 \\
\hline Geometric Mean: & 3.34 & 23.410 & 47.900 & 28.350 & 3.66 & 0.38 \\
\hline Harmonic Mean: & 3.16 & 22.480 & 44.820 & 28.250 & 3.54 & 0.37 \\
\hline Root Mean Square: & 3.70 & 25.330 & 52.700 & 28.550 & 3.87 & 0.39 \\
\hline Trim Mean (10\%): & 3.44 & 23.980 & 50.810 & 28.500 & 3.75 & 0.38 \\
\hline Midrange: & 4.40 & 26.920 & 45.500 & 27.720 & 3.99 & 0.40 \\
\hline Winsorized Mean: & 3.43 & 24.210 & 50.890 & 28.530 & 3.75 & 0.38 \\
\hline TriMean: & 3.48 & 23.520 & 51.000 & 28.100 & 3.79 & 0.39 \\
\hline Standard Deviation: & 1.15 & 6.960 & 15.070 & 2.370 & 0.89 & 0.06 \\
\hline Interquartile Range: & 1.50 & 9.920 & 24.000 & 4.940 & 1.25 & 0.09 \\
\hline Range: & 5.80 & 32.160 & 57.000 & 7.280 & 4.47 & 0.31 \\
\hline Coef. of Variation: & 0.33 & 0.290 & 0.300 & 0.080 & 0.24 & 0.16 \\
\hline Skewness: & 0.66 & 0.590 & -0.310 & -0.310 & -0.06 & -0.06 \\
\hline Kurtosis: & 3.51 & 2.800 & 2.100 & 1.630 & 2.50 & 2.50 \\
\hline
\end{tabular}

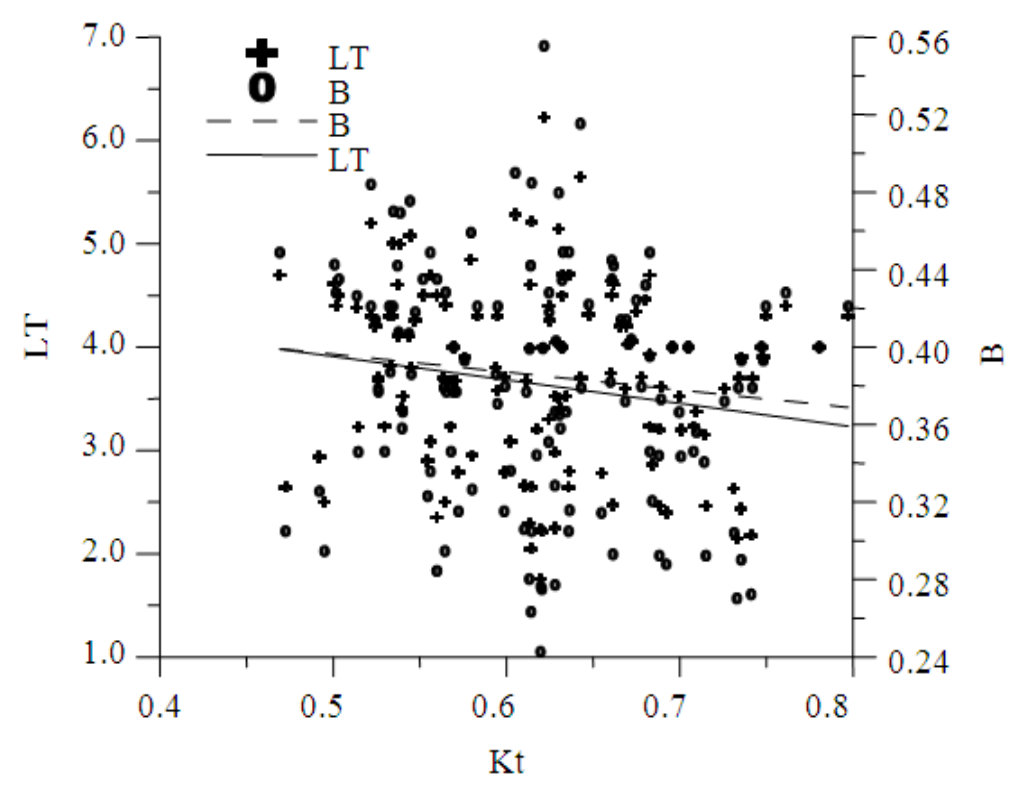

Fig. 6. Relationship between the LT, B and Kt 


\section{DISCUSSION}

Turbidity values are found to be high in the summer and show decreasing trends. LT again shows a slightly increasing trend in Khamassien storm, possibly from the increase of traffic activities during the civilization city as a source of smokes and also because of decreasing mixing height due to the decreasing solar intensity. Similar patterns of variation to that of B (equation 1) are also calculate for LT (equation 2) and $\alpha$ (equation 3). We also found that in the transitional seasons the atmospheric turbidity indices recorded significant high values, due to the effects of anthropogenic air pollutants and due to the particles emitted from the desert. The turbidity parameter Bstarts its higher values from March up to a peak in July $(\approx 0.24)$. It remains high during the autumn, showing a peak in September (0.23). In addition, subsidence inversion is stronger in September and leads to the trapping of pollution in the boundary layer, causing environmental problems in this month. The higher level of diffuse component for Aswan than for Cairo is due to the presence of higher level of coarse particles, which contains particles of large size like sand. The presence of these particles tends to make the diffusion of beam solar radiation become diffuse radiation. In Cairo site, by contrast, it is the smoke, which makes the absorption greater than the diffusion for beam radiation. Figure 6 shows the relation between LT and clearness index $(\mathrm{Kt})$ it clear from the figure that; when the LT is less the Kt is high. Figure 7 shows the relation between LT and Diffuse fraction (KD) it clear from the figure that; when the LT is high the KD is less. Figure 8-10, show the map of monthly variation of WS, LT and B at different latitude at Egypt. Figure 8-9 show the high values of LT (5-6) and B (0.48-0.52) lies between Lat. $28^{\circ} \mathrm{N}$ $30^{\circ} \mathrm{N}$, low values $\mathrm{LT}<3.5$ and $\mathrm{B}<0.3$ below of Lat. $26^{\circ} \mathrm{N}$. If we look at the consequences in Fig. 8-9, it shown that 8 cities (Cairo, Helwan, Alexandria, Ismailia, Al-minya, AlArish, Rafah and Bahtim) of the thirteen city used in the study are located in the maximum values of this period is the most civilized cities and concentrated a large part of the population which constitutes a danger to the health of the population and the spread of diseases resulting from atmospheric turbidity. It is clear that the same maps distribution of LT and B at the minimum and maximum values. By explaining Fig. 8, we find that the maximum value of wind speed between 6.3 to 5.5 during the latitude of $27-28^{\circ} \mathrm{N}$, this means that the maximum value of wind speed, which lies between latitude 27-28 north pay the direction of air pollution, making them participate effectively in the transport of air pollution with limited to the direction of the South. According this work, the stronger climatologically parameters affects on the LT and B is WS.

\subsection{Comparison between Different Years Result at the Same Region}

The comparison between the previous studies for direct solar radiation at true noon and other studies at the same region Helwan, Egypt as shown in Table 6. It can be concluded that the intensity of direct solar radiation decreased by $40-45 \%$ with respect to previous results 1915-1927 (Shaw, 1921), 1967-1977 (Hgazy, 1976), 1991-1996 (Shaltout and Rahoma, 1996) and 19962000. Consequently it is found that, the mean values of LT give us rate increase. A study of these monthly mean variations of total radiation at normal incidence before and after industrial revealed significant is losses due to intense of air pollution in the area in recent year.

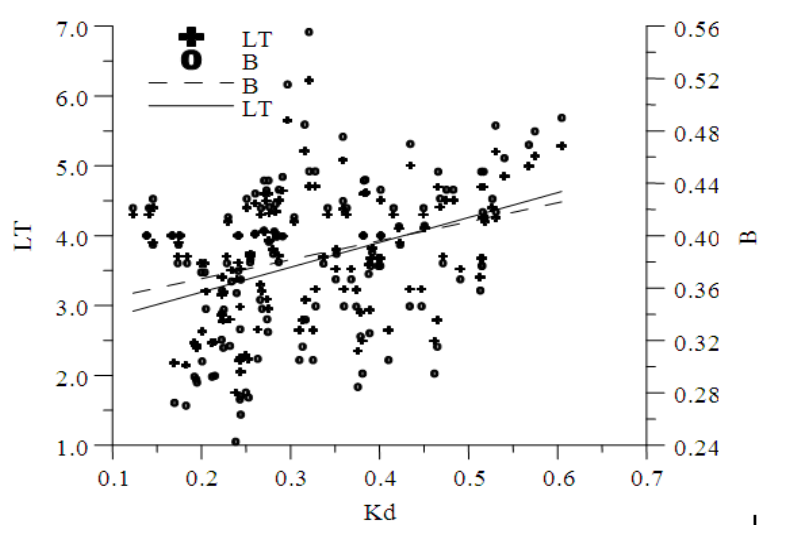

Fig. 7. Relationship between the LT, B and KD

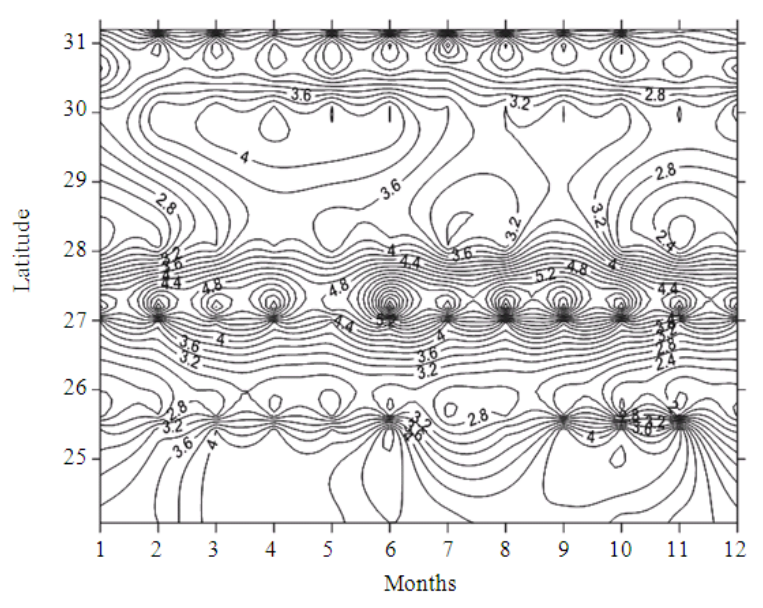

Fig. 8. Map of monthly variation of WS at different attitude at Egypt 
Table 6. Compression between the monthly values for different years For LT at Helwan, Egypt

\begin{tabular}{llllllllllllll}
\hline Helwan & Jan. & Feb. & Mar. & Apr & May & Jun. & Jul. & Aug. & Sep. & Oct. & Nov. & Dec & Mean \\
\hline $1915-1927$ & 2.24 & 2.70 & 3.05 & 3.34 & 3.45 & 3.48 & 3.43 & 3.51 & 3.27 & 2.88 & 2.64 & 2.33 & 3.02 \\
$1967-1977$ & 4.08 & 4.64 & 4.81 & 5.09 & 5.24 & 5.28 & 5.20 & 5.13 & 4.84 & 4.70 & 4.32 & 4.10 & 4.78 \\
$1991-1996$ & 4.35 & 5.02 & 5.21 & 5.20 & 5.36 & 5.35 & 5.43 & 5.54 & 5.22 & 5.15 & 6.14 & 4.30 & 5.18 \\
$1996-2000$ & 4.88 & 5.24 & 5.53 & 5.51 & 5.59 & 5.69 & 5.81 & 5.73 & 5.47 & 5.28 & 6.57 & 4.80 & 5.50 \\
\hline
\end{tabular}

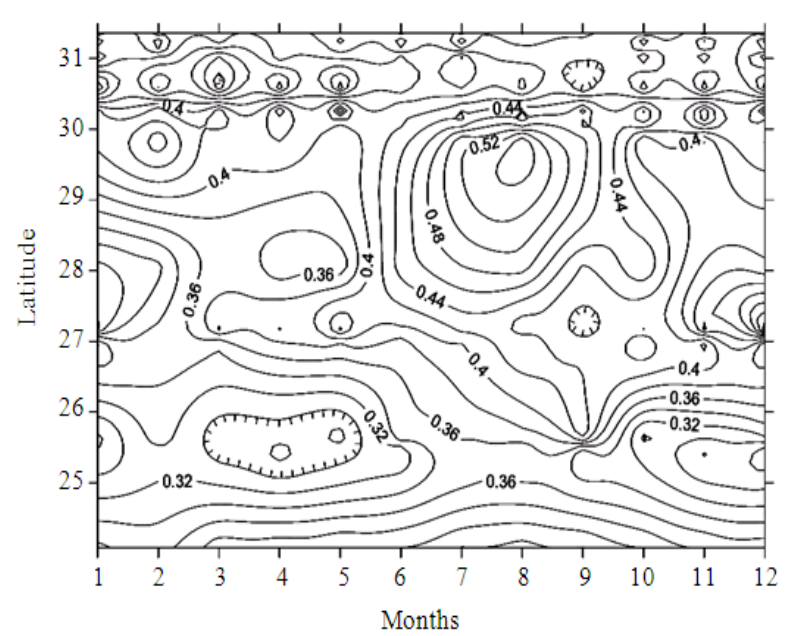

Fig. 9. Map of monthly variation of B at differentLatitude at Egypt

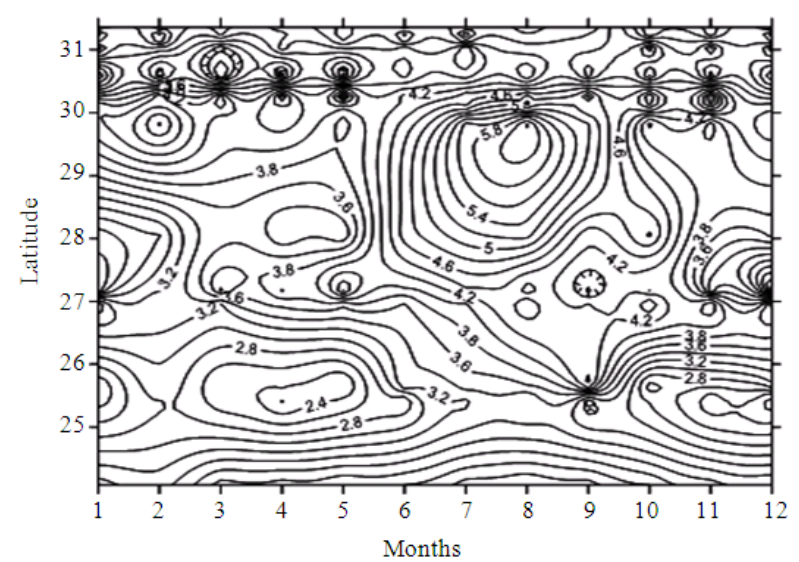

Fig. 10. Map of monthly variation of LT at differentLatitude at Egypt

It can be noticed that the total radiation received in Helwan in previous years highly exceeds that during our study. In order to isolate the influence of air pollutants on diffuse radiation, the dusty days during which the atmospheric visibility usually reduces down to $1-2 \mathrm{~km}$, were scanned. The relationship which link LT and different parameter with correlation coefficient is $90 \%$, given as:

$$
\begin{aligned}
& \mathrm{LT}=-6.82+0.027 \mathrm{Elev}+0.0000167 \mathrm{Elev}^{2} \\
& +0.6 \mathrm{WS}-0.007 \mathrm{Elev} \mathrm{WS}-0.009 \mathrm{WS}^{2} \\
& +0.08 \mathrm{~T}+0.02 \mathrm{RH}+0.19 \varphi
\end{aligned}
$$

The relationship which link B and different parameter with correlation coefficient is $87 \%$ and residual sum of squares $=23.11$, given as:

$$
\begin{aligned}
& \mathrm{B}=-0.36+0.002 \mathrm{Elev}+1.310^{-6} \mathrm{Elev}^{2} \\
& +0.05 \mathrm{WS}-0.0005 \mathrm{Elev} \mathrm{WS}-0.0008 \mathrm{WS}^{2} \\
& +0.005 \mathrm{~T}+0.001 \mathrm{RH}+0.01 \varphi
\end{aligned}
$$

Correlation coefficient $=85 \%$ and residual sum of squares $=0.12$. As we see from equation 4 and 5 , the high parameter affect on the LT and B at the different climatologically parameter are WS, $\varphi, T$, Elev. and $\mathrm{RH}$ respectively.

\section{CONCLUSION}

The urbanization and industrialization have increased very rapidly in Egypt, particularly in the second half of the last century causing an increase in the pollution of its atmosphere. Detailed studies on the effect of urbanization and industrialization on global solar radiation and the percentage values of radiation loss in the atmosphere, at Egypt, have been performed. The data of measured throughout the period from 1969 to 2006 in addition the calculated extraterrestrial solar radiation have been used.

Final results and conclusions could be summarized in the following points:

- The analysis of the monthly variation, it can be concluded that the intensity of direct solar radiation decreased by $40-45 \%$ with respect to previous results 1915-1927, 1967-1977, 1991-1996 and 1996-2000 at Helwan

- From our analysis shows; the high values of LT (5-6) and $\mathrm{B}(0.48-0.52)$ lies between Lat. $28^{\circ} \mathrm{N}-30^{\circ} \mathrm{N}$. low values $\mathrm{LT}<3.5$ and $\mathrm{B}<0.3$ below of Lat. $26^{\circ} \mathrm{N}$

- we find that 8 cities of the thirteen city used in the study are located in the maximum values of this 
period is the most civilized cities and concentrated a large part of the population which constitutes a danger to the health of the population and the spread of diseases resulting from atmospheric turbidity

- The yearly mean of LT values gradually increase from the minimum value of 2.9 during the years 1915-1927 year with average increase rate 5-6 during1996-2000 year

- The high parameter affect on the LT and B at the different climatologically parameter are WS, $\varphi, \mathrm{T}$, Elev and RH respectively

\section{REFERENCES}

Abdelrahman, M.A., S.A.M. Said and A.N. Shuaib, 1988. Comparison between atmospheric turbidity coefficients of desert and temperate climates. Solar Energy, 40: 219-225. DOI: 10.1016/0038092X(88)90044-8

Adeyefa, Z.D. and J.A. Adedokun, 1991. Pyrheliometric determination of atmospheric turbidity in the harmattan season over Ile-Ife, Nigeria. Renew. Energy, 1: 555-566. DOI: 10.1016/09601481(91)90071-V

Angstrom, A., 1929. On the atmospheric transmission of sun radiation and on dust in the air. Geografis. Annal., 2: 156-166.

Angstrom, A., 1961. Techniques of determining the turbidity of the atmosphere. Tellus, 13: 214-223.

ASHRAE, 2009. Handbook Climate Design Data, Inc., Atlanta, GA, USA.

Bird, R.E., 1984. A simple, solar spectral model for direct-normal and diffuse horizontal irradiance. Solar Energy, 32: 461-471. DOI: 10.1016/0038092X(84)90260-3

Diouri, M., L.E. Amraoui, R. Jaenicke and L. Schutz, 2000. Atmospheric turbidity over the Angad area of Morocco. J. Aerosol. Sci., 31: 279-280.

El-Hussainy, F.M. and M.A. Omran, 1998. Analysis and trends of atmospheric turbidity parameters over Cairo. Meteorol. Atmos. Phys., 66: 113-121. DOI: 10.1007/BF01030451

Gueymard, C., 1994. Analysis of monthly average atmospheric precipitable water and turbidity in Canada and Northern United States. Solar Energy, 53: 57-71. DOI: 10.1016/S0038-092X(94)90606-8

Hamdy, K.E., 2006. Relative influence of weather conditions and air pollutants on solar radiation Part 2: Modification of solar radiation over urban and rural sites. Meteorol Atmos Phys., 96: 257-264. DOI: $10.1007 /$ s00703-006-0210-y
Hgazy, N.A., 1976. Effect of air pollution visibility and penetration of solar ultraviolet radiation. Ph.D. Thesis, Cairo University.

Hussain, I., D.J. Powell, D.R. Howlett, G.A. Chapman and L. Gilmour et al., 2000. ASP1 (BACE2) cleaves the amyloid precursor protein at the $\beta$-secretase site. Mol. Cellular Neurosci., 16: 609-619. DOI: 10.1006/mcne.2000.0884

Katz, M., A. Baille and M. Mermier, 1982. Atmospheric turbidity in a semi-rural site-II influence of climatic parameters. Solar Energy, 28: 329-334. DOI: 10.1016/0038-092X(82)90307-3

Leckner, B., 1978. The spectral distribution of solar radiation at the earth's surface-elements of a model. Solar Energy, 20: 143-150. DOI: 10.1016/0038092X(78)90187-1

Linke, E., 1922. Transmission-koeffizient und trubungsfaktor. Beitr. Phys. Atmos., 10: 91-103.

Louche, A., M. Maurel, G. Simonnot, G. Peri and M. Iqbal, 1987. Determination of Angstrom's turbidity coefficient from direct total solar irradiance measurements. Solar Energy, 38: 89-96. DOI: 10.1016/0038-092X(87)90031-4

Pemund, J., L. Wald, M. Lefèvre, T. Ranchin andJ. Page, 2003. Worldwide linke turbidity information. Proceedings of the ISES Solar World Congress, Jun. 16-19, Goeteborg, Sweden.

Rahoma, U.A. and A.H. Hassan, 2010. Estimate of aerosol optical depth using broadband direct normal observations at highest polluted area in the world. Am. J. Applied Sci., 7: 647-655. DOI: 10.3844/ajassp.2010.647.655

Robaa, S.M., 2009. Urban-rural solar radiation loss in the atmosphere of Greater Cairo region, Egypt. Energy Conv. Manage., 50: 194-202. DOI: 10.1016/j.enconman.2008.06.024

Shaltout, M. and U.A. Rahoma, 1996. Solar irradiation at helwan in relation with climatic conditions. Proceedings of the International Workshop on Solar Energy and Environment, Jul. 4-5, Agadir, Marocco.

Shaltout, M., A. Hassan and U. Ali Rahoma, 1998. Measurements of suspended particles and aerosols in atmosphere of Helwan, Egypt. Proceedings of the 6th International Conference on Energy and Environment, May 18-21, Cairo, Egypt, pp: 467-478.

Shaw, H.K., 1921. Observations of Solar Radiation During 1915-1921. 1st Edn., Ministry of Public Works, Egypt, pp: 20.

Zakey, A.S., M.M. Abdelwahab and P.A. Makar, 2004. Atmospheric turbidity over Egypt. J. Atmos. Environ., 38: 1579-1591. 